\title{
Karbapenemaz üreten enterobacteriaceae izolatlarının immünokromatografik kart test RESIST-3 O.K.N. K-SET ile değerlendirilmesi
}

\author{
Evaluation of carbapenemases producing enterobacteriaceae by \\ immunochromatographic card test RESIST-3 O.K.N. K-SET assay
}

\author{
Oktay Yapıcı ${ }^{1} \quad$ Hafize Yapıcı ${ }^{1}$ Nilüfer Saygılı Pekintürk ${ }^{2}$ \\ Alper Akgüneş ${ }^{2}$ Senem Akgül ${ }^{2}$ Bora Ekinci ${ }^{3}$ \\ \begin{tabular}{l}
${ }^{1}$ Manisa Devlet Hastanesi, İnfeksiyon Hastalıkları ve Klinik Mikrobiyoloji Kliniği, Manisa, Türkiye \\
${ }_{2}^{2}$ Manisa Devlet Hastanesi, Tıbbi Mikrobiyoloji Kliniği, Manisa, Türkiye \\
${ }^{3}$ Muğla Sıtkı Koçman Üniversitesi, Sağlık Bilimleri Fakültesi, Muğla, Türkiye \\
\hline
\end{tabular}
}

Öz

Amaç: Son yıllarda, Enterobacteriaceae türlerine karşı artan antimikrobiyal direnç küresel bir sorun olmaya devam etmektedir. $\mathrm{Bu}$ çalışmada karbapenem dirençli Enterobactericeae suşlarında immünokromatografik yöntem ile OXA-48 benzeri, KPC ve NDM beta-laktamaz karbapenemazlarının varlığının araştırılması amaçlanmıştır.

Gereç ve Yöntem: 1 Haziran 2017 ile 31 Mayıs 2018 tarihleri arasında mikrobiyoloji laboratuvarına çeşitli servislerden ve yoğun bakımdan gönderilen 717 Enterobactericeae suşu çalışma kapsamına alındı. Geleneksel yöntemler (koloni morfolojisi, gram boyama vb.) ve otomatize ViTEK-2 sistemi ile tanısı konulan Enterobactericea suşları değerlendirildi. VITEK-2 sistemi ile antibiyogramı yapılan ve EUCAST önerilerine göre en az bir karbapenem grubu antibiyotiğe dirençli tespit edilen izolatlarda, karbapenem direnç tipi RESIST-3 O.K.N. K-SET (Coris BioConcept, Gembloux, Belgium) immünokromatografik yöntemle değerlendirildi.

Bulgular: Değerlendirilmeye alınan Eschericia coli $(n=430)$ ve Klebsiella pneumoniae $(n=210)$, Klebsiella ozanea $(n=4)$, Serratia marcescens $(n=50)$, Serratia odorifa $(n=3)$ arasında 35 karbapenem dirençli suş saptandı. Tespit edilen diğer türler (Salmonella, Enterobacter, Proteus, Citrobacter, Morganella, Yersinia) arasında karbapenem direnci saptanmadı. Enterobactericeae türleri arasında \%4,8 $(n=35)$ karbapenemlere direnç tespit edildi. Klebsiella pneumoniae suşları arasında \%13,3 ( $\mathrm{n}=28)$, Eschericia coli suşları arasında \%0,9 $(\mathrm{n}=4)$ oranında karbapenem direnci tespit edildi. Klebsiella pneumoniae suşlarında $(n=28)$ immünkromatografik yöntemle en fazla OXA-48 benzeri $(n=13 ; \% 48)$ enzim direnci gözlendi. OXA -48 benzeri enzim pozitif saplanan bu 13 suşun 9'u (\%69) kolistine duyarlı bulundu.

Sonuç: İlerleyen yıllarda mikrobiyoloji alanında daha kısa sürede, daha uygun maliyette, yüksek duyarlılık ve seçiciliğe ait bu tür pratik yöntemlerin kullanım alanının artacağını düşünmekteyiz.

Anahtar Sözcükler: Karbapenem direnci, enterobacteriaceae.

\begin{abstract} immunochromatographic method. Belgium) by immunochromatographic method.

\footnotetext{
Yazışma Adresi: Oktay Yapıcı

Manisa Devlet Hastanesi, İnfeksiyon Hastalıkları ve Klinik

Mikrobiyoloji, Manisa, Türkiye

E-mail:yapicio@hotmail.com

Makalenin Geliş Tarihi: 22.08.2018 Kabul Tarihi: 25.10.2018
}

Aim: In recent years, Enterobacteriaceae species have rapidly become a global problem due to the increasing antimicrobial resistance. The aim of this study was to investigate the presence of OXA-48 like KPC and NDM beta-lactamase carbapenemases in carbapenem resistant Enterobactericeae strains by

Materials and Methods: Between June 1, 2017 and May 31, 2018, 717 Enterobactericeae strains were sent to microbiology laboratory from various services and intensive care units. Enterobactericeae strains diagnosed by conventional methods (colony morphology, gram staining etc.) and VITEK-2 system. According to the EUCAST recommendations, at least one carbapenem group antibiotic-resistant isolates was evaluated by carbapenem resistance type RESIST-3 O.K.N. K-SET (Coris BioConcept, Gembloux, 
Results: Thirty-five carbapenem resistant strains were detected between Escherichia coli $(n=430)$ and Klebsiella pneumoniae $(n=210)$, Klebsiella ozanea $(n=4)$, Serratia marcescens $(n=50)$ Serratia odorifa $(n=3)$. No other carbapenem resistance was found between the other species identified (Salmonella, Enterobacter, Proteus, Citrobacter, Morganella, Yersinia). Among the Enterobacteriaceae species, resistance to carbapenem was $4.8 \%(n=35)$. Carbapenem resistance was detected in $13.3 \%(n=28)$ of Klebsiella pneumoniae strains and $0.9 \%(n=4)$ of Escherichia coli strains. In Klebsiella pneumoniae strains, resistance to OXA-48 ( $n=13 ; 48 \%)$ was the most observed by immunochromatographic method. Nine of these 13 strains (69\%) were found to be susceptible to colistin.

Conclusion: In the following years, we believe that the use of such practical methods of high sensitivity and selectivity will increase in a shorter time in the field of microbiology.

Keywords: Carbapenem resistance, enterobacteriaceae.

\section{Giriş}

Son yıllarda, Enterobacteriaceae türleri giderek artan antimikrobiyal direnç nedeniyle global sorun olmaya hızla devam etmektedir. Amerika Birleşik Devletleri'nde karbapenem dirençli Enterobacteriaceae (KDE) insidansı 2.93/100.000 olarak bildirilmiştir (1).

KDE' ye bağlı gelişen enfeksiyonların mortalitesi yüksektir (2). KDE suşlarının saptanması, karbapenemlere duyarlı olmayan izolatların belirlenmesi ve bunu takiben duyarlı olmayan izolatlarda karbapenemaz varlığının doğrulanması şeklinde genel olarak iki basamaklı bir süreci içerir. Doğrulama süreci için geliştirilmiş birçok fenotipik ve genotipik yöntem olup, hepsinin çeşitli avantaj ve dezavantajları bulunmaktadır. Örneğin polimeraz zincir tepkimesi gibi moleküler testler ile doğrulanma süreci yaklaşık olarak 72 saat alan ve yoğun emek gerektiren bir süreçtir. Bu yöntemlerin seçiminde duyarlııı ve özgüllüklerinin yanı sıra yöntemin uygulanacağı sağlık kuruluşunun bölgesel direnç profilinin bilinerek seçim yapılması da önemlidir. Hızlı sonuç veren ve kolay kullanılan bazı analiz yöntemlerinin mikrobiyolojide kullanım alanı yaygınlaşmaktadır. Bu yöntemler arasında yer alan immünokromatografik kart testleri, karbapenemaz tipi belirlenmesi gibi direnç mekanizmalarının saptanmasında, düşük maliyetli, uzun raf ömürlü, yüksek duyarlılık (\%100) ve seçiciliğe (\%100) sahiptir (3-5).

KDE suşlarının antibiyotik direnç paternlerinin saptanması, epidemiyolojik verilerin değerlendirilmesinde, salgın durumları için enfeksiyon kontrol önlemlerinin en kısa sürede alınmasında ve tedavi kararında kritik bir rol oynamaktadır.

$\mathrm{Bu}$ çalışmada hastanemiz yatan hastalarına ait klinik örneklerden izole edilen KDE suşlarında immünokromatografik yöntem ile OXA-48 benzeri (oksasilinaz), KPC (K. pneumoniae karbapenemaz) ve NDM (yeni Delhi Metallo) beta-laktamaz karbapenemazlarının varlığının araştırılması amaçlanmıştır.

\section{Gereç ve Yöntem}

1 Haziran 2017 ile 31 Mayıs 2018 tarihleri arasında mikrobiyoloji laboratuvarına çeşitli servislerden ve yoğun bakımdan gönderilen yatan hastalarına ait kan, idrar ve solunum yolu örneklerinden izole edilen Enterobactericeae suşları çalışmaya dahil edilmiştir. Geleneksel yöntemler (koloni morfolojisi, gram boyama vb.) ve otomatize ViTEK-2 sistemi ile tanısı konulan 717 Enterobactericeae suşu değerlendirilmiştir. VITEK-2 sistemi ile antibiyogramı yapılan ve EUCAST önerilerine göre en az bir karbapenem grubu antibiyotiğe dirençli tespit edilen izolatlarda, karbapenem direnç tipi RESIST-3 O.K.N. K-SET (Coris BioConcept, Gembloux, Belgium) immünokromatografik yöntemle değerlendirilmiştir.

Üretici firmanın önerileri doğrultusunda, \%5 koyun kanlı agar üzerindeki tek koloni 10 damla lizis tamponu içinde süspansiyon haline getirildi. Süspansiyondan üç damla kaset üzerinde ilgili bölüme damlatıldı ve 15 dakika içinde sonuç okundu.

\section{Bulgular}

Toplam 717 Enterobactericeae suşu değerlendirildi. Bu suşlar $E$. coli ( $n$ : 430), ikinci sırada ise $K$. pneumoniae ( $n: 210$ ) tespit edildi. Enterobactericeae türleri arasında arasında \%4,8 (n: 35) karbapenemlere direnç tespit edildi. Tespit edilen diğer türler (Salmonella, Proteus, Enterobacter vb.) arasında karbapenem direnci saptanmadı. Karbapenem direnç tespit edilen suşlar kan kültürü (n: 15), idrar kültürü (n: 14), solunum yolu (n: 6) örneklerinden izole edilmiştir. Örnekler büyük çoğunluğu yoğun bakım hastalarına ( $\mathrm{n}: 22$ ) ait olup daha sonra palyatif bakım servisi ve nefroloji servis hastaları takip etmekteydi. 
Tablo-1. Enterobacteriaceae izolatlarının RESIST-3 O.K.N. K-SET testi ile tespit edilen karbapenem direnç tiplerinin ve tür dağılımı.

\begin{tabular}{llccc}
\hline & RESIST-3 O.K.N. K-SET & Pozitif $(\mathbf{n})$ & Tigesiklin duyarııı̆ı $(\mathbf{n})$ & Kolistin duyarlı̆̆ı $(\mathbf{n})$ \\
\hline Klebsiella pneumoniae & OXA -48 & 13 & 2 & 9 \\
Klebsiella pneumoniae & OXA -48+NDM & 5 & 0 & 1 \\
Klebsiella pneumoniae & Negatif & 10 & 3 & 3 \\
Klebsiella ozanea & OXA- 48 & 1 & 0 & 1 \\
Esherichia coli & OXA- 48 & 2 & 2 & 2 \\
Esherichia coli & Negatif & 2 & 2 & 2 \\
Serratia marcescens & OXA- 48 & 1 & 1 & 0 \\
Serratia odorifa & OXA- 48 & 1 & 1 & 0 \\
\hline
\end{tabular}

Klebsiella pneumoniae suşları arasında \%13,3 (n :28), E. coli suşları arasında \%0,9 (n: 4) karbapenem dirençi tespit edildi. K. pneumoniae suşlarında immünkromatografik yöntemle en fazla OXA-48 benzeri (\%48, n: 13) direnci gözlendi. Beş K. pneumoniae suşunda OXA -48 pozitifliği ile NDM direnci birlikte gözlendi. Karbapenem $K$. pneumoniae suşlarında ( $\mathrm{n}: 28$ ) en fazla kolistin (n: 13) duyarlı tespit edildi. RESIST-3 O.K.N KSET ile OXA-48 benzeri ( $n: 13)$ enzim pozitif saplanan suşun 9'u (\%69) kolistin duyarlı bulunmuştur (Tablo-1).

\section{Tartışma}

Proteobacteria şubesinde, Gamma-proteobacteria sınıfında, Enterobacteriales takımında, Enterobacteriaceae ailesinde yer alan $K$. pneumoniae türleri arasında giderek artan karbapenem direnci global sorun olmaya hızla devam etmektedir. Yaptığımız çalışmada $K$. pneumoniae suşları arasında \%13,3 (n: 28), E. coli suşları arasında \%0,9 (n: 4) karbapenem direnci tespit edildi. Duman ve ark. yaptıkları beş yıllık çalışmada bizim çalışmamızdaki sonuçlara benzer olarak karbapenem dirençli $K$. pneumoniae suşlarını $\% 11,6$, E. coli suşlarında $\% 0,6$ saptarken, bu direncin yoğun bakım hastalarında \%20'ye ulaştığını tespit etmişlerdir (6).

Kazanılmış direnç kapsamına giren karbapenemazlar, Ambler moleküler sınıflamasına göre $A, B$ veya $D$ moleküler sınıflarına ait olabilir. $A$ Sınıf: KPC, B Sınıfı: Metallo ß-Laktamazlar (MBL).
NDM-1, VIM ve IMP, D Sınif: OXA Karbapenemazlar ana temsilcileridir. Bu dirençli suşların etken olduğu enfeksiyonların hem seyri kötü hem de tedavi seçenekleri kısıtıdır $(2,7)$. Tedavi seçenekleri arasında tigesiklin, fosfomisin, aminoglikozidler, seftazidim/avibaktam, kolistin ve karbapenemler yer alır $(8,9)$.

Türkiye'de ilk olarak 2001 yılında Poirel ve 2008 yılında da Aktaş ve ark. tarafından OXA-48 karbapenemaz $K$. pneumoniae bildirilmiştir (10, 11). Daha sonra 2011 de Poirel ve arkadaşları NDM-1 K. pneumoniae bildirmişlerdir (12).

Aslı ve ark. tarafından, Türkiye'de 18 merkezden gönderilen 134 karbapenemaz şüpheli K.pneumoniae izolatları incelenmiş; 103 izolatta $(\% 83,1)$ OXA-48 enzimi yaygın olarak saptanmıştır (13). Bizim çalışmamızda da en sık OXA-48 benzeri karbapenemaz direnci tespit edilmiş olup diğer çalışmalarla uyumlu bulunmuştur (14).

Alp ve ark. 2010-2011 yılları arasında OXA-48 + NDM-1 birlikteliği göstermişleridir (15). Bizim çalışmamızda bu birliktelik K. pneumoniae (n: 5) suşlarında gözlenmiştir.

KPC-2 enzimi ülkemizde 2014 yılında Romanya'dan gelen bir hastada tespit edilmiş olup bizim çalışmamızda kullandığımız bu yöntem ile KPC enzimi varığı saptanmamıştır (16).

KDE tedavi seçenekleri kısıtlıdır. Bunlar arasında karbapenem grubu antibiyotikler (yüksek doz, uzamış infüzyon, ikili kombinasyon) ile birlikte kolistin ve tigesiklin ikili veya üçlü kombinasyonları 
yer almaktadır. Kolistinin nefrotoksik, nörotoksik yan etkilerinin olması, tigesiklinin bakteriyostatik etkili olması ve kan dolaşım enfeksiyonlarında serumda yeterli konsantrasyona ulaşamaması tedavide karşılaşılan diğer sorunlardır (17). Ülkemizde henüz mevcut olmayan Seftazidim/avibaktam Ambler moleküler sınıflamasına göre grup $A$, ve $D$ (Oxa-48)'ye etkili iken grup B metallo Blaktamazlara etkisizdir $(18,19)$.

Çalışmamızda KDE suşların ( $\mathrm{n}$ : 35$) \% 51$ 'i kolistin duyarlı (n:18) bulundu. Karbapemenem dirençli 28 K. pneumoniae suşunun \%46'sı kolistin duyarlı, OXA-48 pozitif $K$. pneumoniae suşlarının \%31'i kolistin dirençli bulunurken Davarcı ve ark. 2013 2014 yılları arasında Türkiye'de yaptıkları çalışmada 32 'i OXA-48 pozitif $K$. pneumoniae suşunda \%8,9 kolistin direnci saptamışlardır (20).

\section{Sonuç}

Enterobacteriaceae suşlarında karbapenemaz direncinin saptanması, epidemiyolojik verilerin değerlendirilmesinde, salgın durumları için enfeksiyon kontrol önlemlerinin en kısa sürede alınmasında ve tedavi kararında kritik bir rol oynamaktadır.

\section{Kaynaklar}

1. Alice $Y$, Guh MD, Bulens SN, Mu Y, et al. Epidemiology of Carbapenem-Resistant Enterobacteriaceae in 7 US Communities. 2012-2013. JAMA. 2015 Oct 13; 314 (14): 1479-87.

2. Balkan II, Aygün G, Aydın S, et al. Blood stream infections due to OXA-48-like carbapenemase-producing Enterobacteriaceae: treatment and survival.Int $\mathrm{J}$ infect Dis. $2014 \mathrm{Sep}$; 26: 51-6.

3. Sağıroğlu P, Hasdemir U, Altınkanat Gelmez G, et al. Performance of "RESIST-3 O.K.N. K-SeT" immunochromatographic assay for the detection of OXA-48 like, KPC, and NDM carbapenemases in Klebsiella pneumoniae in Turkey. Brazilian Journal of Microbiology Available online 1 March 2018.

4. Wareham DW and Momin MHFA, Abdul Momin_ et al. Rapid Detection of Carbapenemases in Enterobacteriaceae: Evaluation of the RESIST-3 O.K.N (OXA-48, KPC, NDM) Multiplexed Lateral Flow Assay. J. Clin. Microbiol. Accepted manuscript posted online 1 February 2017.

5. Glupczynski $Y$, Jousset A, Evrard S, et al. Prospective evaluation of the OKN K-SeT assay, a new multiplex immunochromatographic test for the rapid detection of OXA-48-like, KPC and NDM carbapenemases. J Anticrob Chetmother. 2017 Jul 1; 72 (7): 1955-60.

6. Yucel Duman, Cigdem Kuzucu, Mehmet Sait Tekerekoglu et al. Changing trends of carbapenem resistance of escherichia coli and klebsiella pneumoniae strains isolated from intensive care units, inpatient services and outpatient's clinics: a five years retrospective analysis Available online 18.06.2018. with doi: 10.5455/medscience

7. Zubair A. Qureshi, David L Paterson, et al. Treatment Outcome of Bacteremia Due to KPC-Producing Klebsiella pneumoniae: Superiority of Combination Antimicrobial Regimens Antimicrob Agents Chemother 2012 Apr; 56 (4): 2108-13.

8. David van Duin, Keith S Kaye, Elizabeth A et al. Carbapenem-resistant Enterobacteriaceae: a review of treatment and outcomes Diagn Microbiol Infect Dis. 2013 February; 75 (2): 115-20.

9. Matthew E Falagas, Panagiota Lourida, Panagiotis Poulikakos, Petros I Rafailidis and Giannoula S Tanserli. Antibiotic Treatment of Infections Due to Carbapenem-Resistant Enterobacteriaceae: Systematic Evaluation of the Available Evidence Antimicrob Agents Chemother. 2014 Feb; 58 (2): 654-63.

10. Laurent Poirel Claire Heritier Venus TolünClaire Héritier and Patrice Nordmann Patrice Nordman. Emergence of Oxacillinase-Mediated Resistance to Imipenem in Klebsiella pneumoniae Antımıcrobial agents and chemotherapy. 2004 Jan.:15-22.

11. Aktaş Z, Kayacan CB, Schneider I, Can B, Midili K, Bauernfeind A. Carbapenem-hydrolyzing oxacillinase, OXA48, persists in Klebsiella pneumoniae in Istanbul, Turkey. Chemotherapy 2008; 54 (2): 101-6.

12. Laurent P, Melda Ö, Alain A et al. NDM-1-Producing Klebsiella pneumoniae Now in Turkey Antimicrob Agents Chemother. 2012 May; 56 (5): 2784-5.

13. Aslı Ç, Yakut A, Deniz G, et al. Türkiye'de 2014 Yılı İçinde İzole Edilen Karbapeneme Dirençli Escherichia coli ve Klebsiella pneumoniae İzolatlarında Karbapenemaz Varlığının Araştırıması Mikrobiyol Bul 2016; 50 (1): 21-33. 
14. Kilic A, Aktaş Z, Bedir O, et al. Identification and characterization of OXA-48 producing, carbapenem-resistant Enterobacteriaceae isolates in Turkey. Ann Clin Lab Sci. 2011 Spring; 41 (2): 161-6.

15. Alp E, Perçin D, Colakoğlu S, et al. Molecular characterization of carbapenem-resistant Klebsiella pneumoniae in a tertiary university hospital in Turkey Journal of Hospital Infection 2013; 84: 178-80.

16. Labarca J, Poirel L, Özdamar M, Türkoglu S, Hakko E and Nordmann_P. KPC-producing Klebsiella pneumoniae, finally targeting Turkey New Microbes New Infections 2014: 2014 Mar; 2 (2): 50-5.

17. Morrill HJ, Pogue JM, Kaye KS, La Plante KL. Treatment Options for Carbapenem-Resistant Enterobacteriaceae Infections. Open Forum Infect Dis. 2015 May 5; 2 (2).

18. Aktas Z, Kayacan C, Oncul O. In vitro activity of avibactam (NXL104) in combination with betalactams against Gram-negative bacteria, including OXA-48 beta-lactamase-producing Klebsiella pneumoniae. International journal of antimicrobial agents 2012; 39 (1): 86-9.

19. Castanheira M, Farrell SE, Krause KM, Jones RN, Sader HS. Contemporary diversity of betalactamases among Enterobacteriaceae in the nine U.S. census regions and ceftazidimeavibactam activity tested against isolates producing the most prevalent beta-lactamase groups. Antimicrobial agents and chemotherapy 2014; 58 (2): 833-8.

20. İsmail D, Seniha Ş, Mert AK et al. Karbapenem dirençli K. pneumoniae suşlarında OXA-48 direnç geninin araştırılması. tmc-online.org/image/37 kongre/ss-40.pdf. 